\title{
Toisième partie - Les moyens au service des entreprise / Présentation
}

Maurice Wolkowitsch

\section{(2) OpenEdition}

\section{Journals}

Édition électronique

URL : https://journals.openedition.org/rhcf/1319

DOI : 10.4000/rhcf.1319

\section{Éditeur}

Rails \& histoire

\section{Édition imprimée}

Date de publication : 10 février 2004

Pagination : 223

ISBN : 0996-9403

ISSN : 0996-9403

\section{Référence électronique}

Maurice Wolkowitsch, « Toisième partie - Les moyens au service des entreprise / Présentation », Revue d'histoire des chemins de fer [En ligne], 30 | 2004, mis en ligne le 23 août 2012, consulté le 22 avril 2022. URL : http://journals.openedition.org/rhcf/1319 ; DOI : https://doi.org/10.4000/rhcf.1319

Ce document a été généré automatiquement le 22 avril 2022

Tous droits réservés 


\section{Toisième partie - Les moyens au service des entreprise / Présentation}

Maurice Wolkowitsch 
1 Les entreprises ne peuvent vivre qu'après avoir acquis le matériel et recruté les hommes indispensables au fonctionnement du système complexe qu'est un chemin de fer, même s'il s'agit de quelques kilomètres de lignes. Dans un précédent chapitre, nous avons analysé les moyens en matériel et en hommes dont disposaient des entreprises de très inégales importances; nous avons aussi, en nous appuyant sur des exemples concrets, cherché à connaître quels étaient les fondateurs des réseaux secondaires et les administrateurs qui en ont assuré la gestion, avec plus ou moins de bonheur.

2 C'est une optique différente que nous adoptons maintenant en poursuivant deux objectifs. En premier lieu, nous nous proposons de dresser un état des matériels et des effectifs employés par les chemins de fer secondaires, en précisant l'évolution constatée dans la première décennie du $\mathrm{XX}^{\mathrm{e}}$ siècle. En second lieu, nous souhaitons, au moyen d'un indice, établir des comparaisons entre les dotations en matériel et en personnel enregistrées suivant les compagnies ou les lignes. Les hommes dont nous allons parler sont sur le " terrain », du piqueur à l'ingénieur en chef; on les trouve dans les gares, les trains, les dépôts et sur la voie; d'eux dépendent l'efficacité de l'entreprise ${ }^{1}$.

3 Le fonctionnement des chemins de fer secondaires suppose des moyens semblables à ceux des grandes compagnies. La recherche par les grands réseaux de normes communes n'a pas sa réplique dans le monde des chemins de fer secondaires, étant donné le nombre et la diversité des entreprises. La volonté constante d'économiser conduit à une simplification des procédures et des équipements dans des domaines aussi divers que la signalisation, la communication entre les gares, la maintenance des matériels ou la hiérarchie des personnels.

INDEX

Mots-clés : aménagement du territoire, chemin de fer, exploitation ferroviaire, France, infrastructure ferroviaire, politique des transports/France, chemin de fer secondaire

\section{AUTEUR}

\section{MAURICE WOLKOWITSCH}

Professeur émérite à l'université de la Méditerranée 